\title{
De volta para o futuro: tecnologias e agenciamentos entre livros e leituras1
}

\author{
Taynée Mendes VIEIRA ${ }^{2}$ \\ Márcio Souza GONÇALVES ${ }^{3}$
}

Resumo:

O presente artigo revisita o pensamento de autores clássicos da história do livro para levantar pontos de tensão relevantes para a discussão da leitura no universo digital. Trata-se aqui, sobretudo, de problematizar uma visão linear dessas histórias, da leitura em voz alta, durante a Idade Média, à informatização do escrito, no fim do século XX, abrindo espaço para uma concepção complexa e nuançada da relação entre leitura, tecnologia e cultura na história. Apresenta-se inicialmente a visão geralmente aceita dos principais momentos que marcaram a história do livro - a invenção da escrita, o surgimento do códice e a recente digitalização -, a fim de discutir alguns pressupostos importantes para entender a leitura hoje. Por fim, conclui-se que se deve evitar uma visão histórica linear e investir na ideia de que há diversos agentes além do tecnológico para se estudar e compreender diferentes práticas de leitura.

Palavras-chave: História do livro. Práticas de leitura. Manuscrito. Impresso. Digital.

\section{Back to the future: technologies and agency in books and readings}

\begin{abstract}
:
This article intends to revisit some authors of the book history to tension some relevant points to discuss reading practices in the digital field. We will, especially, problematize the linear vision of these histories, from reading aloud, during Middle Ages, to computerization of the written word, at the end of 20th century, giving space to a complex and nuanced conception of the relationships among reading, technology, and culture. At first, the vision generally accepted of the main moments of book history is presented - the creation of writing, the emergence of the codex, and the recent digitalization - in order to discuss some important assumptions that could help us to understand reading today. Finally, it is concluded that we should avoid a linear historical vision and rather promote the idea that there are different agents beyond the technology to study and understand different reading practices.
\end{abstract}

Keywords: History of the book. Reading practices. Manuscript. Printing. Digital.

\section{De vuelta al futuro: tecnologías y agencias entre libros y lecturas}

\begin{abstract}
Resumen:
Este artículo revisita el pensamiento de escritores clásicos de la historia del libro para levantar puntos de tensión a fin de discutir la lectura en el universo digital. Sobretodo, vamos a problematizar una visión linear de estas historias, desde la lectura en voz alta, durante la Edad Media, a la informatización del escrito, en fines del siglo $\mathrm{XX}$, abriendo espacio a una concepción compleja y matizada de la relación entre lectura, tecnología y cultura. Al inicio, presentase la visión de los principales momentos de la historia del libro - la invención de la escrita, el surgimiento del códice y la recién digitalización - para discutir hipótesis importantes para entender la lectura hoy. Al fin, es concluido que debemos evitar una visión histórica lineal e invertir en la idea de que hay diferentes agentes además del tecnológico para estudiar y comprender distintas prácticas de lectura.
\end{abstract}

Palabras clave: Historia del libro. Prácticas de lectura. Manuscrito. Impreso. Digital.

\footnotetext{
${ }^{1}$ Uma versão preliminar do presente texto foi apresentada no GP Produção Editorial, do XVII Encontro dos Grupos de Pesquisa em Comunicação, evento componente do $40^{\circ}$ Congresso Brasileiro de Ciências da Comunicação em Curitiba (PR), em 2017.

${ }^{2}$ Mestre em Comunicação pela Universidade do Estado do Rio de Janeiro (UERJ), participante do Laboratório de Investigação de História da Comunicação da UERJ.E-mail: taynee.mendes@ gmail.com.

3 Doutor em Comunicação pela Universidade Federal do Rio de Janeiro (UFRJ), Bolsista Prociência UERJ/FAPERJ, Professor do Programa de Pós-graduação em Comunicação da UERJ. E-mail: msg@uerj.br.
} 


\section{Introdução}

Em 1998, Bill Gates afirmou: "Os e-books prometem revolucionar a forma como o mundo lê" (Apud GOGGIN; HAMILTON, 2012, p. 110). ${ }^{4}$ Dita no fim dos anos 90 - época em que os computadores pessoais para uso doméstico se popularizavam -, a frase epitomiza a visão de que as novas tecnologias teriam um impacto absolutamente profundo no modo como nos relacionamos com os livros e a leitura. O uso do verbo "revolucionar" põe em cena uma ideia, muito comum naquele momento, de um corte radical com o passado.

Conforme apontam Goggin e Hamilton (2012, p. 103) em seu estudo sobre leitura em celulares, frases como a do empresário norte-americano podem ser tendenciosas, pois é preciso colocar a tecnologia em uma perspectiva histórica e comparativa, na medida em que permite "a crítica dos mitos e narrativas sobre leitura e esta nova forma de mídia". 5

Do ano da frase até hoje, foram vários os aparelhos dedicados à leitura, desde $e$ readers - exclusivamente dedicados a livros e revistas - até dispositivos mais abrangentes como smartphones e tablets, que funcionam basicamente como computadores que também servem à leitura. Ler livros é, claramente, uma possibilidade presente em diferentes suportes nos dias atuais.

O presente artigo procura construir bases para buscar entender a "leitura no digital", revisitando alguns autores da história do livro e da leitura. As aspas da frase anterior se justificam na medida em que a leitura no digital ou feita em mídias digitais é frequentemente entendida como diferente de leituras outras, supostamente com características próprias, ou, na visão de Bill Gates, revolucionária. A intenção é tensionar a visão que está por trás de alguns marcos específicos da história da leitura. Assim, começaremos por discutir criticamente o tema da leitura na Antiguidade e na Idade Média. Passaremos, em seguida, para a questão da leitura em máquinas digitais e sua relação com leituras do passado.

\section{No princípio era a voz: a leitura na Grécia Antiga}

Para a reflexão acerca da tecnologia, tomaremos inicialmente, como caso de análise, a questão da emergência de uma leitura silenciosa. Verifica-se que, dentre autores da história do livro e da leitura (BARBIER, 2005; MANGUEL, 2006; CAVALLO; CHARTIER, 1998; FISCHER, 2005), é disseminado o entendimento de que a passagem de uma leitura em voz alta, comum na Antiguidade clássica, para uma leitura silenciosa, predominante no final da

\footnotetext{
4 "[...] e-books promise to revolutionize the way the world reads". A tradução de todos os textos citados em língua estrangeira no texto é nossa.

5 “[...] a critique of the myths and narratives concerning reading and this new media form".
} 
Idade Média, foi um grande marco, com imensas consequências sociais, psicológicas e epistemológicas. Analisaremos como essa questão foi canonicamente abordada para, posteriormente, problematizar tal tratamento a fim de nuançar a reflexão em torno das tecnologias de comunicação.

É praticamente um lugar comum teórico o papel da tecnologia, e sobretudo da tecnologia alfabética, nesse processo. Para Jesper Svenbro (1998, p. 41), a escrita alfabética "irrompe" na cultura grega de tradição oral, mas essa irrupção não anula a enorme proximidade entre escrita e oralidade. Para esse autor, o leitor só chegaria ao sentido do texto com o uso do som - o que implicava um esforço considerável -, e que envolvia a forma como as palavras se apresentavam graficamente sobre o suporte de escrita. Svenbro (1998, p. 44) se refere à scriptio continua, a escrita sem separação entre palavras, o que tornava "a leitura lenta e hesitante, provocando irresistivelmente a intervenção da voz". A leitura em escrita contínua implicava a necessidade de se ler em voz alta para entender o texto.

Segundo Cavallo e Chartier (1998), as ilustrações áticas mostram principalmente homens, mas depois também mulheres, participando do ato da leitura em contextos recreativos. "Esses leitores não são solitários, em geral, aparecem em contextos representativos de entretenimento e de conversação, sinal de que a leitura era vista, sobretudo, como prática de vida em sociedade" (CAVALLO; CHARTIER, 1998, p. 11). Para eles, a leitura solitária, embora conhecida, era rara, pelos poucos testemunhos iconográficos ou literários que sobreviveram.

Ler, na Grécia, assim, remeteria a ler em voz alta. Cavallo e Chartier (1998, p. 11) ressaltam que a leitura oralizada advinha da necessidade de tornar compreensível o sentido de uma scriptio continua, que "seria ininteligível e inerte sem a enunciação em voz alta". No entanto, os autores também afirmam, referindo-se ao trabalho "Silent reading in antiquity", de Bernard Knox (1968), que há relatos de práticas de leitura silenciosa em uma época muito antiga. Segundo Cavallo e Chartier (1998), os primeiros testemunhos de Eurípedes e de Aristófanes referentes à leitura silenciosa remetem ao final do século V a.C. e dizem respeito a objetos diferentes do livro (uma mensagem sobre uma tabuinha e a resposta de um oráculo). Apesar de não serem propriamente livros, os autores questionam: "é preciso indagar se nessa mesma época, em algumas situações, não se praticava também uma leitura silenciosa do livro" (CAVALLO; CHARTIER, 1998, p. 11).

Para Steven Roger Fischer (2005, p. 47), no século V a.C., a leitura deixou de ser 
monopólio de uma oligarquia que dela se aproveitava para validar seu poder e se tornou uma ferramenta "popular" de acesso a informações na Grécia. Essa força do escrito se nota no fato de que Tucídides (c. 460-395 a.C.), segundo Fischer (2005, p. 47), confiava mais em documentos escritos do que nas tradições orais para compilar uma cronologia e avaliar eventos passados: "Percebia-se, nesse momento, que a escrita permitia a complementação e a retenção de textos em um grau que a oralidade jamais conseguiria alcançar”.

Segundo o historiador Frédéric Barbier (2005), no início, a escrita ocupava linhas longas abertas no sentido longitudinal (o rotulus era aberto verticalmente), já depois a disposição de colunas foi mais frequente (o volumen era aberto horizontalmente). Para ele, esse formato proporcionava uma prática complexa de leitura, o que "impedia, por exemplo, trabalhar com muitos rolos ao mesmo tempo (um texto e seu comentário) ou tomar notas, já que impunha uma leitura continuada e impedia a simples consulta" (BARBIER, 2005, p. 25). ${ }^{6}$

De fato, ler um rolo de papiro não era simples. Era necessário desenrolá-lo seguidas vezes, retornar e avançar caso o leitor quisesse navegar pelo texto; procurar determinada passagem era complicado. Não havia sumários ou índices. Para fechar o rolo e armazená-lo de modo adequado era preciso enrolá-lo novamente até o início (ficar aberto podia causar danos). Era um objeto caro e precioso. "Se houvesse um incêndio na casa, os volumina eram, sem dúvida, as primeiras coisas a serem salvas depois das crianças” (FISCHER, 2005, p. 63).

A equação bem estabelecida entre escrita contínua e leitura oralizada recebeu minuciosa atenção de Robert McCutcheon, de um modo que, para nós, importa bastante. Crítico de uma abordagem "evolucionista" da história do livro, e, mais especificamente, do surgimento da leitura em silêncio, este autor aponta para o fato de que a crença, comum, na ideia de que o surgimento da leitura silenciosa foi um divisor de águas revela muito acerca da epistemologia da história do livro, de certa história do livro, que se "encaixa perfeitamente dentro de uma narrativa maior que a disciplina da história do livro gosta de oferecer sobre a evolução dupla do livro e da mente humana" (MCCUTCHEON, 2015, p. 2) e que cai, em certa medida, no que alhures denomina-se epocalismo (GONÇALVES; CLAIR, 2007). Mas antes de tratar da contribuição de McCutcheon, vejamos rapidamente a questão do códice e de sua presença cultural.

\footnotetext{
6 “[...] impedía, por ejemplo, trabajar con muchos rollos al mismo tiempo (un texto y su comentario) o tomar notas, ya que imponía una lectura continuada e impedía la simple consulta".
} 


\section{O códice e a leitura silenciosa na Idade Média}

Alguns autores - como Cavallo e Chartier (1998) e Lyons (2011), por exemplo consideram a invenção do códice ou códex um evento significativo e duradouro na história do livro. Com o códice, o livro assumiu o formato material que reconhecemos habitualmente como "livro". A substituição do rolo pelo códice foi gradual. Lyons afirma que a monarquia inglesa ainda se valia do rolo para registrar sua legislação na Idade Média; durante um bom tempo o rolo também foi usado no teatro, dando origem ao termo inglês role, o "papel de um ator" (LYONS, 2011, p. 37).

Os cristãos primitivos foram os primeiros a adotar o novo formato e os primeiros códices da Bíblia em papiro datam do século II. Para Lyons (2001), a questão identitária religiosa era importante nessa adoção: os judeus tradicionalmente liam o Pentateuco em rolos e assim é possível que os cristãos usassem o códice para distinguir, fisicamente, suas escrituras da Torá. Outra razão importante nessa popularização cristã do códice, destacada por Manguel (2006), reside no fato de esse formato ser mais facilmente transportado e escondido nas vestes dos cristãos, caso quisessem manter certa discrição.

O romano Marco Valério Marcial (38-104 d.C), o primeiro a citar a novidade, elogia as vantagens do códice e ressalta o quanto ele libera espaço na biblioteca, além de poder ser lido com apenas uma das mãos (Apud FISCHER, 2005). O códice possibilitava, ainda, que o estudioso acrescentasse números de páginas (o que perdurou mesmo depois da prensa) e criasse índices que permitiam a localização de textos e de citações específicas, que podiam remeter a outros códices. Cabeçalhos e resumos podiam ser acrescentados, e "esses utensílios foram essenciais para o uso do texto como instrumento de ensino" (LYONS, 2001, p. 37).

Cavallo e Chartier (1998) consideram o aparecimento do códice como uma resposta a uma larga demanda de leitura na sociedade romana. Segundo os autores, Roma manteve a forma física do volumen e certas práticas de leitura da Grécia, sobretudo no começo do século II a.C. A época imperial marca uma nova etapa nas práticas de leitura, principalmente pelo progresso na alfabetização e pela vasta circulação da cultura escrita. Ao lado de inscrições de todo o tipo, circulava uma multidão de escritos: cartazes, libelos, prospectos em verso ou prosa, calendários, documentos, cartas, mensagens. Nesse cenário, manifesta-se uma crescente demanda por livros, que encontra resposta em três planos: criação de bibliotecas públicas e incrementos de particulares; oferta de textos novos destinados a novos públicos; e produção e distribuição de um tipo diferente de livro, o códice, mais adequado às 
necessidades desses novos leitores (CAVALLO; CHARTIER, 1998).

Barbier (2005, p. 40) relaciona o formato códice à emergência da leitura silenciosa: "Do ponto de vista de uso imediato, podia-se consultar o códice fazendo anotações, o que permitiu abandonar a leitura oral para privilegiar o trabalho intelectual em silêncio". 7 Ao relacionar o trabalho intelectual à leitura silenciosa e à possibilidade de fazer anotações, o autor induz ao raciocínio de que o trabalho intelectual está ligado ao desenvolvimento dessa tecnologia, ecoando a dupla relação entre história do livro e desenvolvimento da mente humana apontada por McCutcheon (2015).

O códice é visto como um elo de transição entre a leitura na Antiguidade e a leitura na Idade Média. Para Cavallo e Chartier (1998), a mudança tecnológica foi acompanhada também por processos culturais, sociais e políticos. A Idade Média marcou uma fratura profunda no Ocidente latino no campo da leitura.

\begin{abstract}
A leitura do ócio literário que, no mundo antigo se realizava geralmente entre jardins e arcadas e que previa também praças e ruas urbanas como espaços de escritas expostas [...] foi substituída pela prática de leitura concentrada no interior das igrejas, das celas, dos refeitórios, dos claustros, das escolas religiosas, algumas vezes das cortes: leituras, aliás, geralmente limitadas às Sagradas Escrituras e a textos de edificação (CAVALLO; CHARTIER, 1998, p. 20).
\end{abstract}

Os autores atribuem à Alta Idade Média na Europa o período de "passagem da leitura em voz alta para uma leitura silenciosa ou murmurada" (CAVALLO; CHARTIER, 1998, p. 21). Eles não creditam apenas à separação de palavras e ao códice essa mudança, pois havia outros fatores, dentre os quais o espiritual: os livros eram lidos para conhecer Deus, de forma que deviam ser compreendidos, repensados, eventualmente memorizados e o próprio códice facilitava releituras, confrontos e convidava a uma leitura meditada; por outro lado, a vida comunitária dos círculos religiosos obrigava a falar em voz baixa. O livro, nem sempre destinado à leitura, mostra-se, além do trabalho piedoso e instrumento de salvação, "como bem patrimonial e em suas formas mais elevadas, preciosas, monumentais, torna-se sinal do sagrado e do mistério" (CAVALLO; CHARTIER, 1998, p. 21). Veremos que essa visão "monumental" do livro, associado ao formato códice, permanece até hoje e pode explicar, em parte, a dificuldade de aceitação do livro, visto como algo elevado, em plataformas digitais corriqueiras, como o celular (GOGGIN; HAMILTON, 2012).

\footnotetext{
7 "Desde el punto de vista de su uso inmediato, se podía consultar el codex tomando anotaciones, lo que permitía abandonar la lectura oral para privilegiar el trabajo individual en silencio".
} 
A apresentação do texto começou a melhorar com a reforma de Carlos Magno (742814). Como os bárbaros falavam a língua vulgar, diferente do latim, fez-se necessário analisar o latim para poder traduzi-lo, daí uma reforma na escrita que conduziu à minúscula carolíngia, com o objetivo de combater a variabilidade de letras empregadas, facilitando a leitura e o trabalho mental dos eruditos (GONÇALVES; TIMPONI, 2012). Segundo Barbier (2005), nesse período, começaram a aparecer outras inovações além da difusão da minúscula carolíngia: a separação de palavras, certa insinuação de pontuação e divisões internas nos códices. Deste modo, "o programa do Renascimento carolíngio ilustra como nenhum outro a estreita relação que existia entre as exigências políticas, as formas culturais e a organização do sistema de difusão dos medias" (BARBIER, 2005, p. 50). ${ }^{8}$

Do final do século XI até XIV, tem-se uma nova situação social. Renascem as cidades e, com as cidades, as escolas, que são os lugares do livro. A alfabetização se desenvolve, a escrita progride em todos os níveis, os usos do livro se diversificam. De acordo com Cavallo e Chartier (1998), o modelo de leitura escolástica universitária impregna profundamente o escrito. Feita para o estudo, a página escrita acaba assumindo uma tipologia funcional. Aperfeiçoa-se um sistema de técnicas auxiliares de leitura e de consulta do livro destinadas a identificar rapidamente a passagem que se procura: rubricas, sinais de parágrafos, títulos de capítulos, separação de texto e comentário, sumário e índices em ordem alfabética (CAVALLO; CHARTIER, 1998). Em suma, técnicas que visam a facilitar a leitura e o estudo. Mas nesse universo de elementos, a separação de palavras ganha destaque, principalmente por estar relacionada à leitura silenciosa.

\section{Práticas de leitura e modos de escrita}

Um dos excertos clássicos que sustenta o argumento de que os leitores antigos não liam silenciosamente se encontra nas Confissões, de Santo Agostinho, que comenta a atividade de seu mestre Ambrósio, considerada por ele como incomum:

Ao ler, corria os olhos pelas páginas: a mente penetrava o significado, enquanto a voz e a boca se calavam. Muitas vezes ao entrarmos (pois a ninguém era proibido o ingresso nem precisava anunciar-se), o víamos lendo, sempre em silêncio. [...] Talvez evitasse ler em voz alta, para não ser obrigado por algum ouvinte curioso e atento a explicar alguma passagem difícil do autor, ou a discutir alguma questão por demais complexa. [...] Talvez, lendo baixo, também quisesse apenas poupar a voz, que se enfraquecia facilmente (AGOSTINHO, 2009, p. 142-143).

\footnotetext{
8 “[...] el programa del Renacimiento carolingio ilustra como ninguno la estrecha relación que existía entre las exigencias políticas, las formas culturales y la organización del sistema de difusión de los medias".
} 
Segundo McCutcheon (2015), o filólogo Eduard Norden examinou essa passagem em 1898 em sua monografia Die antike Kunstprosa (A antiga arte da prosa, em tradução livre) e conjecturou que ler em voz alta era a prática usual na Antiguidade para textos literários, pela estranheza com que Agostinho encara a leitura de seu mestre, procurando justificativas para a prática silenciosa, como se essa não fosse comum na época. Nas edições subsequentes, listava outros exemplos em um apêndice que demonstrava seu argumento.

No fim dos anos 1920, os classisistas Josef Balogh e G.L. Hendrickson popularizaram a tese de que os antigos leitores não liam em voz alta. O mais influente dos dois, Balogh reuniu uma série de exemplos da literatura clássica para demonstrar que os indivíduos na Antiguidade clássica comumente liam em voz alta uma série de textos e raramente liam de maneira silenciosa. Entre os exemplos, o retórico Lucian de Samosata (século II d.C.) castiga um bibliófilo desta forma: "Seus lábios estão ainda ocupados com uma frase enquanto seus olhos estão na próxima." (H. W. FOWLER; F. G. FOWLER, 1905 apud MCCUTCHEON, 2015, p. 4) ${ }^{9}$. E o poeta Ovídeo escreveu: "Eu tinha medo, mas eu li a sua carta sem emitir som (sine murmure), antes que minha língua involuntariamente jure por algum Deus" (BALOGH, 1927 apud MCCUTCHEON, 2015, p. 4). ${ }^{10}$ Então, Balogh ofereceu um raciocínio com base na tecnologia, apontando a causa da suposta raridade da leitura silenciosa na Antiguidade: a scriptio continua. Para Balogh (Apud MCCUTCHEON, 2015), os leitores superavam a dificuldade de ler textos contínuos apenas ao articular o texto em voz alta para assim perceber os finais de cada palavra.

E o mesmo nexo causal entre os pares "escrita contínua/leitura em voz alta” e "separação de palavras/leitura silenciosa" está presente nos teóricos da história do livro.

A inserção de espaços entre as palavras, que se tornara padrão no século XI nas Ilhas Britânicas (onde existia desde o século VII), na França e na região da Alemanha, teve como "primeira consequência diminuir a necessidade de se ler em voz alta para compreender o texto" (SAENGER, 1998, p. 147). Saenger também associava a leitura silenciosa rápida a um reconhecimento visual da forma das palavras e da percepção da organização espacial do texto, o que envolvia a separação entre palavras.

Malcolm Parkes (1998, p. 110), estudioso da pontuação no Ocidente, alega que os escribas irlandeses, ao copiarem textos latinos, abandonaram a escrita contínua dos seus

\footnotetext{
9 "Your lips [are] still busy with one sentence while your eyes are on the next".

10 "I was afraid, but I read your letter without a sound (sine murmure), lest my unwitting tongue swear by any Gods".
} 
exemplares: "eles separavam as palavras, introduzindo espaços em branco entre as partes da oração". Para Parkes (1998, p. 110), essa prática foi desenvolvida “em resposta às necessidades de leitores para os quais o latim era uma segunda língua”.

A primazia do olho sobre a voz, com o advento da leitura silenciosa como prática social comum, e suas implicações cognitivas foram trabalhadas por diversos autores. Segundo McCutcheon (2015), essa tese é compartilhada por quase todos os teóricos da palavra escrita: Marshall McLuhan, Eric Havelock, Jack Goody e Ian Watt, Walter Ong, Lucian Febvre e Henri-Jean Martin, David Olson, Robert Darnton, Alberto Manguel, Steven Roger Fischer, Martyn Lyons e Roger Chartier. De acordo com os autores citados, essa prática permitiu mais reflexão sobre os textos, possibilitando uma expansão do entendimento humano (Apud MCCUTCHEON, 2015). Em suma, haveria assim uma substituição progressiva, ao longo da Idade Média, da leitura oralizada para a silenciosa, com grandes consequências cognitivas e sociais. Tal substituição seria tributária da separação entre as palavras.

A perspectiva teórica é, porém, diferente entre os classicistas. Um contra-argumento bastante simples foi utilizado por W. P. Clark, em 1931. Sobre a passagem de Santo Agostinho anteriormente mencionada, ele afirma: "A surpresa da parte de Agostinho não pode ter sido o fato de que Ambrósio estava sempre lendo em silêncio?” (CLARK, 1931 apud MCCUTCHEON, 2015, p. 6, grifo do autor). ${ }^{11}$ Alguns autores, segundo McCutcheon (2015), também questionam por que a prática cultural de ler em voz alta necessariamente marginaliza a leitura silenciosa. McCutcheon (2015) considera que o raciocínio tecnológico apresentado para explicar a leitura silenciosa como rara simplifica demais uma questão histórica complexa. Por exemplo, os textos apresentavam certa pontuação, mas esta não era padronizada; no século II a.C. os textos latinos apresentavam pontos entre palavras (interpuncta), segundo o modelo etrusco; e, mais fundamental, a scriptio continua se tornou predominante nos textos latinos até o século II d.C. Ora, se a separação entre palavras foi tão revolucionária para a leitura silenciosa, por que os romanos retornariam à prática com a escrita contínua? (MCCUTCHEON, 2015, p. 6).

Para esse autor, o argumento de que a escrita contínua tornava a leitura uma tarefa complexa, exequível apenas com a enunciação da voz, pode ser rebatido com um simples experimento, aqui reproduzido e adaptado ao nosso idioma: estafraseemportuguêsemescritacontínuapodeconfirmarisso pode ser lida em voz baixa após vencido o estranhamento inicial. Também, segundo McCutcheon (2015), é importante lembrar

11 "Might not the surprise on the part of Augustine be due to the fact that Ambrose was always found reading silently?" 
que o grego e o latim primeiramente geram significados por meio do uso de casos gramaticais e conjugações verbais, em vez da ordem de palavras, como no inglês. O tailandês e o chinês são línguas que usam a escrita contínua, e seus falantes são perfeitamente capazes de ler em silêncio, embora a separação facilite a leitura. Por isso, "deveríamos ter cuidado ao supor que as práticas bibliográficas ocidentais fornecem as únicas normas aceitáveis, enquanto outras práticas (como a scriptio continua) são vistas como inerentemente falhas e inferiores" (MCCUTCHEON, 2015, p. 7-8). ${ }^{12}$

McCutcheon (2015, p. 8, 12-13) menciona alguns exemplos da literatura clássica que parecem confirmar o argumento segundo o qual na Antiguidade havia tanto leitura silenciosa quanto leitura em voz alta. A discussão sobre a prevalência da leitura oralizada na Antiguidade parece validar a afirmação de Robert Darnton: "a leitura permanece como o estágio mais difícil de se estudar no circuito seguido pelos livros" (DARNTON, 1982, p. 74). ${ }^{13}$ Para McCutcheon (2015), o debate é de difícil abordagem, pois um exemplo de uma prática de leitura é contrabalanceado por outra contrário.

Por que, então, a suposição parcial e tendenciosa sobre a prática de leitura dos antigos ainda é popular entre os autores do livro? E por que a valorização da técnica de separação de palavras, dentre outras, é entendida como fator determinante da leitura silenciosa? Na opinião do estudioso, além de um confirmation bias (a tendência de confirmar algo em que se acredita), de um consenso estabelecido por muitas décadas (MCCUTCHEON, 2015), a tese se encaixa na supracitada narrativa da evolução dupla das tecnologias e da mente humana, das mudanças tecnológicas engendrando mudanças cognitivas.

\section{De volta para o futuro: práticas do presente e do passado}

Cavallo e Chartier (1998) contam-nos que a transmissão eletrônica de textos e as maneiras de ler que ela impõe indicam uma "revolução" da leitura, a partir do final do século $X X$. De fato, ler em uma tela não é ler em um códice. Segundo os autores, a nova representação do escrito modifica a noção de contexto, em que diversos textos estão presentes em um mesmo objeto (livro, revista ou jornal na tela do computador). Outro aspecto novo consiste na "materialidade" das obras, quebrando o elo físico que existia entre o objeto impresso (ou manuscrito) e o texto que ele veicula, "dando ao leitor, e não mais ao autor ou

\footnotetext{
12 " $[\ldots]$ we should exercise caution in assuming that modern Western bibliographic practices provide the only acceptable standards, while other practices (such as scriptio continua) are inherently faulty and inferior".

13 "Reading remains the most difficult stage to study in the circuit followed by books".
} 
editor, o domínio sobre o contorno ou a aparência do texto que ele faz aparecer na tela" (CAVALLO; CHARTIER, 1998, p. 30).

Ainda que sejam muitas as possibilidades dos textos eletrônicos, os autores da história do livro aqui trabalhados percebem semelhanças de atitudes e posturas do leitor contemporâneo se comparados aos leitores antigos. Por exemplo, a configuração em que o texto aparece aos poucos na tela está presente em quase todos os atuais dispositivos midiáticos destinados à leitura - dos PCs aos tablets e smartphones - e alguns autores do livro comparam a atual prática de leitura com algo daquela dos antigos leitores do volumen. Para Barbier (2005, p. 25), "em seu fundamento, a leitura do volumen é muito similar a do computador, com a tela correspondendo à passagem do texto desenrolado aos olhos do leitor". ${ }^{14}$ Manguel (2006) destaca a noção de conjunto que o leitor do códice possuía em comparação ao leitor do rolo e, atualmente, das telas.

Os desajeitados rolos possuíam uma superfície limitada - desvantagem da qual temos hoje aguda consciência, ao voltar a esse antigo formato de livro em nossas telas de computador, que revelam apenas uma parte do texto de cada vez, à medida que "rolamos" para cima ou para baixo. O códice, por outro lado, permitia que o leitor pulasse rapidamente para outras páginas e assim retivesse um sentimento de totalidade - sentimento composto pelo fato de que em geral o texto inteiro permanecia nas mãos dele durante toda a leitura (MANGUEL, 2006, p. 151).

Em sua fala, Manguel (2006) deixa transparecer certo descontentamento quanto à volta de um formato de livro antigo, o rolo. Para Fischer (2005), a obra completa, em formato códice, era

[...] um corpo compacto de informações, deixando pra trás o desfazer sequencial de rolos de papiro conectados entre si. O leitor dispunha assim de uma totalidade acessível. Desde então, essa percepção modificada da literatura foi preponderante. (Somente hoje o 'enrolar' retorna ao modo grego - de cima para baixo -, uma vez que a tela do computador altera as percepções modernas referentes à leitura.) (FISCHER, 2005, p. 79).

Cavallo e Chartier (1998) também notaram semelhanças. No computador, o texto se desenrola verticalmente e é dotado de referências próprias do códice, como a paginação, índice, tabelas, etc. Há, então, um cruzamento das duas lógicas - a do volumen e a do códice que "indica claramente que está estabelecida uma relação totalmente original e inédita com o

\footnotetext{
14 "En su fundamento, la lectura del volumen es muy similar a la del ordenador, con la pantalla que se corresponde con pasaje de texto desenrollado a ojos del lector".
} 
texto" (CAVALLO; CHARTIER, 1998, p. 30). Por conseguinte, essa transformação do suporte do escrito obriga o leitor a novos gestos e novas práticas intelectuais.

Do codex à tela, o passo é tão importante quanto o que foi dado ao passar do rolo ao codex. Com ele, é a ordem dos livros que foi dos homens e das mulheres do Ocidente desde os primeiros séculos da era cristã que está em causa. São assim afirmadas ou impostas novas maneiras de ler que ainda não foram possíveis de caracterizar totalmente mas que, sem a menor dúvida, implicam práticas de leitura sem precedentes (CAVALLO; CHARTIER; 1998, p. 32).

Nota-se, assim, a importância atribuída à tecnologia na determinação das práticas de leitura

McCutcheon (2015) observa haver, dentre os autores da história do livro, quatro eventos, em geral, destacados: 1) a invenção da escrita alfabética; 2) a mudança do rolo para o códice e o suposto surgimento da leitura silenciosa; 3) a invenção da imprensa e maior disseminação de informação padronizada e aumento do público; 4) a atual mudança para a mídia digital com a possibilidade de se armazenar mais informações em um ambiente hipertextual. Nessa perspectiva, o texto digital é visto como "a apoteose do livro em uma forma não corpórea, mas onipresente" (MCCUTCHEON, 2015, p. 18). ${ }^{15}$ Ademais, segundo ele, é comum se referir ao livro como um objeto que tem um "ciclo de vida", do nascimento (publicação) para a vida (circulação e consumo), ou se referir ao manuscrito como a infância do livro; o códice, como a vida adulta; e o rolo, como o "ancestral". Para o autor, essas metáforas não são apenas retóricas:

Neste caso, essas metáforas biológicas revelam que vemos o livro em algum nível como equiparável a espécies vivas, evoluindo e se desenvolvendo para uma determinada forma. Essa visão é parte da ideologia geral de uma "substituição" que molda nosso entendimento da tecnologia da informação, em que cada nova forma de tecnologia representa um avanço tecnológico importante e uma ruptura decisiva com o passado (MCCUTCHEON, 2015, p. 18$).{ }^{16}$

Essa perspectiva, além do caráter problemático de sua linearidade, também aponta para uma visão "monumental" dos livros. Goggin e Hamilton (2012) defendem que, em virtude da aparente estabilidade da página impressa, é fácil desconsiderarmos o livro como

\footnotetext{
15 "[...] the apotheosis of the book into a noncorporeal yet omnipresent form".

16 "In this case, these biological metaphors reveal that we view the book on some level as akin to a living species, evolving and developing toward a certain form. Such a view is part and parcel of the general ideology of "supersession" that informs our understanding of information technology, wherein each new form of the technology represents an important technological advance and decisive break with the past".
} 
uma tecnologia de comunicação bastante adaptável e o vermos como um monumento imóvel. Desde o século V a.C, a ideia do "livro" e sua função prática sempre estiveram em desenvolvimento contínuo. Monumentalizar o livro e sua história e perder de vista o caráter adaptável e plástico dos livros podem obscurecer o entendimento das práticas de leitura em mídias eletrônicas:

Quando naturalizado ou visto como monumento, o lugar do livro como uma mídia é ignorado. Essa atitude também negligencia a oportunidade de entender as atuais práticas de leitura em dispositivos eletrônicos como parte de uma prática contínua da produção e consumo do livro, em vez de atividades opostas à cultura impressa (GOGGIN; HAMILTON, 2012, p. 106). ${ }^{17}$

Em vez de monumentalizar o códice, ou os formatos digitais, como se queira, trabalhando com a ideia de cortes radicais e revoluções, talvez seja mais interessante historicizar as diferentes mídias, permitindo o estabelecimento de aproximações insuspeitadas. Do mesmo modo, em vez de pensar uma sequência linear de tipos de leitura (primeiro oralizada, depois silenciosa) acionada por inovações tecnológicas (separação de palavras), propomos investir na ideia de que possamos ler em um mesmo momento histórico de diferentes modos e de que essa leitura não é determinada exclusivamente pelas características materiais da tecnologia de apresentação de texto utilizada.

\section{Considerações finais}

Recapitulamos rapidamente alguns aspectos da história do livro no sentido de tensionar, a partir de McCutcheon, a ideia de uma sucessão linear de práticas de leitura que estariam ligadas a formas de apresentação do texto (escrita contínua/separação de palavras) e suportes tecnológicos específicos (volumen/códice/computadores). A análise nos ajuda a delinear pelo menos algumas conclusões pertinentes.

A primeira delas é sobre a tendência do campo da Comunicação de considerar as diversas tecnologias como os principais agentes causadores de mudanças na sociedade e, por consequinte, na mente humana. Essa visão encontra eco nas diferentes abordagens da história do livro, em que se destaca uma série de "revoluções" nas quais estilos de escrita e suporte de livros desempenham um papel crucial. Muitas vezes a valorização da tecnologia em detrimento de condições culturais e sociais mais amplas pode obscurecer o entendimento de

\footnotetext{
17 "When normalize or monumentalized, the book's place as a media format is ignored. This attitude also overlooks the opportunity to understand current practices of reading on electronic devices as part of a continuing practice of book production and consumption, rather than activities oppositional to print culture".
} 
uma questão complexa, como a leitura, campo cujo domínio é do leitor, que tem certa liberdade para decidir como ler um texto e conferir significados a ele, em diferentes momentos históricos.

Em decorrência da primeira, a segunda conclusão se refere à aparente ideologia de "substituição", em que novos suportes tecnológicos estariam ocupando o lugar em definitivo de seus antecessores, produzindo assim, no caso da palavra escrita e do livro, novas práticas de leitura. O texto impresso não substituiu o texto manuscrito, e o livro digital não substituiu o livro em papel. Por isso, procuramos sugerir, brevemente, que há outros fatores, além do tecnológico, a serem levados em conta na determinação das práticas de leitura de forma que é preferível investir na idéia de coexistências em lugar daquela de uma sucessão linear de práticas de leitura.

Além disso, a visão ocidental do livro como algo "monumental" não contribui para sua compreensão como objeto cultural bastante flexível. O tensionamento do passado deve permitir desmonumentalizar nossa percepção do códice e compreendê-lo dentro de uma perspectiva histórica, que já demonstrou que os livros são uma mídia bastante adaptável ao seu contexto. Ler no digital não deveria ser visto como algo oposto a ler no impresso ou manuscrito, mas entendido como uma prática complementar às práticas já existentes. Dessa forma, os e-books não "revolucionaram" a forma como o mundo lê, como disse Bil Gates, pois guardam semelhanças com outros formatos anteriores. Portanto, para compreender a leitura em nossas máquinas digitais cotidianas - seja no tablet, e-reader, celular ou algum outro novo suporte a ser inventado - faz-se necessária uma compreensão mais nuançada e complexa, e portanto menos unidimensional, da história dos livros. 


\section{Referências}

AGOSTINHO, Santo. Confissões. São Paulo: Paulus, 2009.

BARBIER, Frédéric. Historia del libro. Madrid: Alianza Editorial, 2005.

CAVALLO, Guglielmo; CHARTIER, Roger. História da leitura no mundo ocidental. São Paulo: Ática, 1998. v. 1.

DARNTON, Robert. What is the history of books? Daedalus, v. 111, n. 3, p. 65-83, Summer, 1982. Disponível em:

https://dash.harvard.edu/bitstream/handle/1/3403038/darnton_historybooks.pdf Acesso em: 28 fev. 2021.

FISCHER, Steven Roger. História da leitura. São Paulo: Editora Unesp, 2005.

GOGGIN, Gerard; HAMILTON, Caroline. Reading after the phone: e-readers and mobile media. In: ARCENEAUX, Noah; KAVOORI, Anandam (ed.). The mobile media reader. New York: Peter Lang, 2012. p. 102-119.

GONÇALVES, Márcio Souza; TIMPONI, Raquel. Suportes textuais de comunicação e processos cognitivos. In: REGIS, Fátima; ORTIZ, Anderson; AFFONSO, Luiz Carlos; TIMPONI, Raquel (org.). Tecnologias de comunicação e cognição. Porto Alegre: Sulina, 2012. p. 52-78.

GONÇALVES, Márcio Souza; CLAIR, Ericson Saint. Antes Tarde do que nunca: notas sobre as contribuições de Gabriel Tarde para a análise da articulação entre comunicação e cultura. Revista Galáxia, São Paulo, n. 14, p. 137-148, dez. 2007.

KNOX, Bernard M. W. Silent reading in antiquity. Greek, Roman and Byzantine Studies, v. 9, n. 4, p. 421-435, July, 1968. Disponível em:

https://grbs.library.duke.edu/article/view/10731. Acesso em: 27 fev. 2021.

LYONS, Martyn. Livro: uma história viva. São Paulo: Editora Senac, 2011.

MANGUEL, Alberto. Uma história da leitura. São Paulo: Companhia das Letras, 2006.

MCCUTCHEON, R. W. Silent reading in Antiquity and the future history of the book. Book History, v. 18, p. 1-32, 2015. Disponível em: https://muse.jhu.edu/article/597277. Acesso em: 27 fev. 2021.

PARKES, Malcolm. Ler, escrever, interpretar o texto: práticas monásticas na Alta Idade Média. In: CAVALLO, Guglielmo; CHARTIER, Roger. História da leitura no mundo ocidental. São Paulo: Ática, 1998. v. 1.

SAENGER, Paul. A leitura nos séculos finais da Idade Média. In: CAVALLO, Guglielmo; CHARTIER, Roger. História da leitura no mundo ocidental. São Paulo: Ática, 1998. v. 1.

SVENBRO, Jesper. A Grécia arcaica e clássica: A invenção da leitura silenciosa. In: 
CAVALLO, Guglielmo; CHARTIER, Roger. História da leitura no mundo ocidental. São Paulo: Ática, 1998. v. 1.

Submetido em 19.09.2019

Aprovado em 28.09.2020 